\title{
Population Distribution Evolution Characteristics and Shift Growth Analysis in Shiyang River Basin
}

\author{
Minzhi Chen', Peizhen Wang'2, Li Chen ${ }^{3}$ \\ ${ }^{1}$ Institute of Urban Planning and Design, Nanjing University, Nanjing, China \\ ${ }^{2}$ The School of Architecture and Urban Planning, Nanjing University, Nanjing, China \\ ${ }^{3}$ The High School Attached to Northwest Normal University, Nanjing, China \\ Email: chenminzhi@hotmail.com,wangzhen_1018@126.com
}

Received 1 August 2014; revised 27 August 2014; accepted 16 September 2014

Copyright (C) 2014 by authors and Scientific Research Publishing Inc.

This work is licensed under the Creative Commons Attribution International License (CC BY). http://creativecommons.org/licenses/by/4.0/

\section{Open Access}

\section{Abstract}

In recent years, the population size and scale of the Shiyang River Basin unceasingly expanding lead to a series of ecological environment: surface water reducing, land desertification and Ground water levels fall, etc. Research evolution characteristics of population distribution and migration growth of Shiyang River Basin contribute to river water resources and the industrial development of the comprehensive management. The article using the distribution of population structure index, population distribution center of gravity model and the population migration growth analysis model analyzes the distribution of the population evolution characteristics and population migration growth characteristics of Shiyang River Basin in 2000 to 2010. The results show that: 1) Considering Shiyang River Basin, population density is generally low, population distribution difference is bigger and concentration distribution in the middle corridor plain and three big population distribution center of Minqin oasis area, presenting a "point-areas-ribbon" structure characteristics. 2) The population distribution trend of Shiyang River Basin is constantly concentration, but the change is slow; the population distribution of Minqin is in the highest concentration degree, but the trend has been declining. 3) The focus of population density in river basin locates in Liangzhou district of Daliu country; in ten years, it migrates about $1209 \mathrm{~m}$ to southwest Wuwei City direction, but migration along the direction things is bigger than the north and south direction. The focus of population density and the basin geometry center is far away. 4) For ten years, at the township for basic statistics unit, each level population migration change within the overall is not significant: township level > prefecture-level cities level > counties level. 5) For ten years, there are significant changes in population migration between watershed township units, Wuwei City and Gulang Town are the two main concentrations of population centers. 


\section{Keywords}

\section{Shiyang River Basin, Population Distribution, Evolution Characteristics, Shift Growth Analysis}

\section{Introduction}

Generally, population distribution refers to manifestations of the population process in the space, and characterization of population groups in the geo-spatial distribution, distribution, and portfolio position [1] [2]. Staggered distribution of the vast desert, Gobi and oasis landscape have created the unique characteristics of the population distribution of Hexi area, in recent years, population number and size in the midstream of the Shiyang River Basin area constantly expanding lead to a series of social and ecological environment in Minqin oasis area of river basin downstream: surface water reducing, land desertification, ground water levels fall and ecological migrants [3]. Water resources management of Shiyang River Basin becomes the basin development bottleneck. In the three watersheds of north-west inland river, Shiyang River Basin has become a basin with the highest level of soil and water resources development, the biggest ecological crisis, the strongest relationship between people and land. Study of the relationship between population and the environment of the Shiyang River Basin not only is concerned about the size of the population, but also cares about the spatial distribution of population characteristics. So we can set out water resources allocation program which is suitable for the distribution of population characteristics of the basin. Therefore, the study of the Shiyang River Basin population distribution of the evolution of character and demographic offset growth characteristics, revealing the basin spatial distribution of population characteristics and laws is conducive to the integrated management of river basin water resources and industrial development, achieving coordination sustainable developments between people and environment.

At present, the study of domestic population distribution is more concentrated at the national provincial unit [4] [5], city and county units of regional and municipal unit [2] [6] [7], within the urban area space unit [8], but the study based on watershed area [9] and township units is relatively small. Research methods make more use of the uneven distribution of population index and the concentration index model, the Lorenz curve model, dispersion model, the population distribution in the center of gravity model, the population offset sharing model, spatial autocorrelation model, the spatial distribution function of simulation models and other model, through quantitative calculation of the population distribution and the spatial distribution reflects the regional distribution of population characteristics. Using the imbalance index and the concentration index model, the population distribution in the center of gravity model and the population offset growth analysis model, based on previous results and the township unit scale to reveal the characteristics of spatial distribution of population of the Shiyang River Basin lays the foundation for population and environment relationship for further study in Shiyang the basin.

\section{Study Area, Data Sources and Processing}

Shiyang River Basin is one of three inland river basins in the Hexi Corridor, the basin area is $4.06 \times 10^{4} \mathrm{~km}^{2}$, located at $101^{\circ} 07^{\prime}-104^{\circ} 15^{\prime} \mathrm{E}, 37^{\circ} 07^{\prime}-39^{\circ} 27^{\prime}$, the river basin administrative divisions include Liangzhou of Wuwei City, Minqin County, Gulang County and some areas of the Tianzhu Tibetan Autonomous County, Jinchuan District of Jinchang City, Yongchang County, and all Sunan Autonomous County of Zhangye City. There are two major river systems: Tai Jing River and West River, as well as the East river, West Camp River, Golden Tower River, Zamu River, Gazelle River, Gulang River as the main body of River System. The basin is arid continental inland climate zones, with less precipitation and precipitation variability, uneven distribution of the year, evaporation and drought periods significantly. In 2009, there was a total population of 1748.8 thousand, achieved a GDP of 17.929 billion yuan, the total grain output reached 950,800 tons, the per capita net income of farmers reached 3972 yuan.

Graphic data set used in this paper is provided by Environmental and Ecological Science Data Center for West China, National Natural Science Foundation of China (http://westdc.westgis.ac.cn). Because the river township zoning unit is frequently adjusted, collecting various of information and data validation, merger and 
name on the part of the township area, and ultimately get 97 township units. Townships appeared in the paper are the name after mergerring. In the year of 2000 and 2010, demographic data comes from counties Bureau of Statistics Statistical Yearbook and various statistical data within the basin: 2010 preliminary data of Liangzhou comes from Sixth Census; 2010 population data of Tianzhu is calculated and adjusted based on 2000-2005 population; 2010 population data of Minqin is 2009 data, although there is discrepancy of population data within a small area, it does not affect the overall population distribution of the basin as a whole.

\section{Research Methods}

Population distribution structure index [2] [6] [7]. The most commonly used index of population distribution changes is the population density, but centralized and decentralized regional population trend are often represented by the imbalance index and the concentration index of population distribution. The calculated formula is respectively shown in formula (1) (2):

$$
\begin{gathered}
U=\sqrt{\frac{\sum_{i=1}^{n}\left[\frac{\sqrt{2}}{2}\left(y_{i}-x_{i}\right)\right]^{2}}{n}} \\
C=\frac{1}{2} \sum_{i=1}^{n}\left|y_{i}-x_{i}\right|
\end{gathered}
$$

$U$ : imbalance index, $C$ : concentration index, $n$ : the Administrative Region of the number, $y_{i}$ : each administrative unit population accounts for the proportion of the total population of the region, $x_{i}$ : each administrative unit land area accounts for the proportion of the total area of the region as a whole. Population imbalance index $U$ and the concentration index $C$ are greater, indicating that the population distribution is more concentrated; otherwise, it showed that the more balanced population distribution.

Gravity model of population distribution [1] [2] [7] [9]. The change of the regional population distribution center of gravity can measure the overall mobile trend of population distribution. Calculating the population distribution center of gravity learns from physical principles, and use population number or population density for the property instead of the physical meaning of the "weight", regarding population attributes of administrative units in the study area as weights to strike spatial centroid. Calculated fomula is:

$$
\bar{x}=\frac{\sum_{i=1}^{n} p_{i} x_{i}}{\sum_{i=1}^{n} p_{i}}, \quad \bar{y}=\frac{\sum_{i=1}^{n} p_{i} y_{i}}{\sum_{i=1}^{n} y_{i}}
$$

$x$ and $y$ represent barycentric coordinates of the population distribution of the study area, $p_{i}, x_{i}, y_{i}$, respectively represents population and the population distribution barycentric coordinates of the various administrative units in the study area. Because the administrative center adjusts frequently, $\left(x_{i}, y_{i}\right)$ is the center coordinates of each administrative unit. When the property value of $p_{i}$ is the area of the administrative unit, the Barycentric coordinates becomes the geometric center of the region, and accordingly it can study the stability of the regional population distribution center of gravity.

Population shift growth analysis [1] [9]-[11]. The process of population offset using shift-share analysis method can analyze the evolution of spatial pattern of intra-regional population. The method was first proposed in 1942 by Creamer and applied to national resources and industrial structure adjustment, and later widely used in regional economic growth [7], in recent years, it has been used in the spatial structure and competition pattern of port system [10] and competitive analysis of tourist destinations [11]. Period of time, studying regional population growth can be decomposed into "sharing" and "shift" in two parts, share growth refers to the amount of growth when the growth of a Administrative Region unit to the population growth rate of the entire region. Offset growth refers to deviation amount that population growth to the amount of share growth. Its value is positive, indicating that the unit population growth is faster, relative to the average level, population gathers to the region; its value is negative indicating that the unit population growth is slower, relative to the average level, population spreads out from the region. Its formula is as follows: 


$$
\begin{aligned}
& \operatorname{SHIFT}_{i}=\mathrm{ABSGR}_{i}-\mathrm{SHARE}_{i}=\mathrm{POP}_{i t_{1}}-\left(\sum_{i=1}^{n} \mathrm{POP}_{i t_{1}} / \sum_{i=1}^{n} \mathrm{POP}_{i t_{0}}\right) \mathrm{POP}_{i t_{0}} \\
& \text { VOLSHIFT }_{\text {intra }}=\sum_{j=1}^{m} \operatorname{VOLSHIFT~}_{\text {intra }_{j}} \\
& \operatorname{VOLSHIFT~}_{\text {intra }_{j}}=\frac{\sum_{i=1}^{r}\left|\operatorname{SHIFT}_{i j}\right|-\left|\sum_{i=1}^{r} \operatorname{SHIFT}_{i j}\right|}{2} \\
& \operatorname{VOLSHIFT}_{\text {inter }}=\sum_{j=1}^{m}\left(\left|\sum_{i=1}^{r} \operatorname{SHIFT}_{i j}\right| / 2\right) \\
& \operatorname{VOLSHIFT}_{\text {total }}=\left(\sum_{i=1}^{n}\left|\operatorname{SHIFT}_{i j}\right|\right) / 2=\operatorname{VOLSHIFT}_{\text {intra }}+\operatorname{VOLSHIFT}_{\text {inter }}
\end{aligned}
$$

$\mathrm{ABSFR}_{i}, \mathrm{SHARE}_{i}, \mathrm{SHIFT}_{i}$ relatively is the amount of absolute growth, the amount of share growth and the amount of offset growth of $i$ administrative unit (township) in $\left(t_{0}, t_{1},\right)$ time. VLISHIFT intra $_{\text {in }}$ is the growth of the total offset between the different administrative units within the same county (township). VOLSHIFT inter $_{\text {is }}$ the growth of the total offset between the different counties. VOLSHIFT ${ }_{\text {total }}$ is the total amount of the offset growth between the various administrative units of the entire study area (township). $m$ is the number of Counties, $n$ is the number of township units, $r$ is the number of counties contained within county districts.

\section{Analysis Results}

Analysis of basin population distribution. In 2010, the total population of Shiyang River Basin is 2.28 million people, the population density is 60 persons/square kilometer, the average population density of 97 townshiplevel unit (including a variety of public places, etc.) is 341 persons/square kilometer. Using Quartile method to classify the basin population density (expressed as a percentage), and take the population density outside the scope of [FU $\pm 3(\mathrm{FU}-\mathrm{FL})]$ as outliers and individually graded, including FU for the last four scores, FL for the next four scores. As shown in Figure 1, the population distribution of the Shiyang River Basin has large spatial differences and the relative concentration, the population was concentrated in the middle reaches corridor plains area and Minqin oasis area, including three population distribution regions: Liangzhou central and western and Gulang County north-west region nearby the Liangzhou, Jinchang Central region, Minqin oasis population concentrated area, forming Concentrated area of population that Wuwei urban, Jinchang City, Minqin County of the

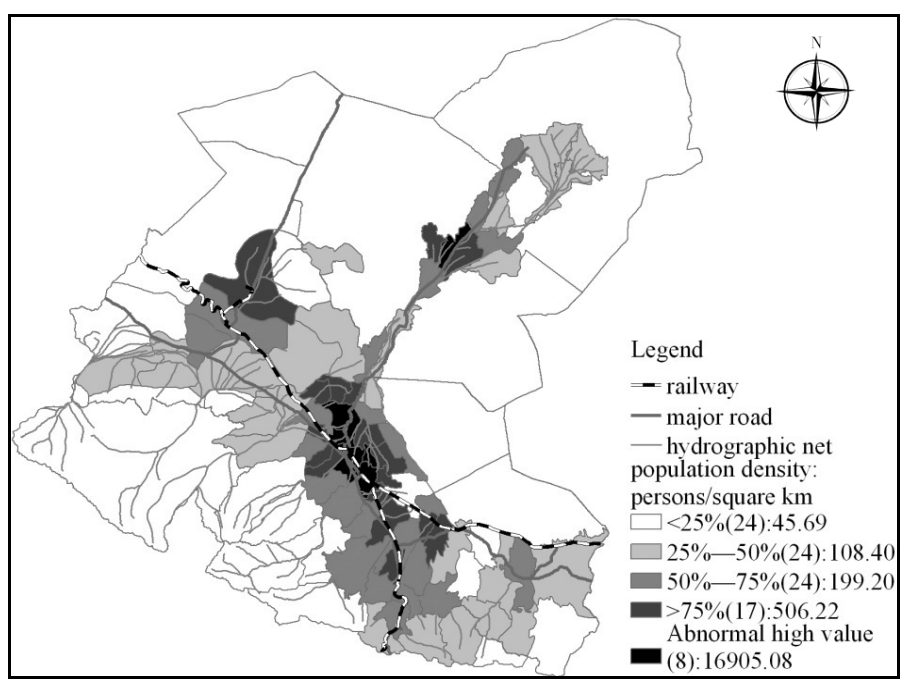

Figure 1. Distribution of population density in the Shiyang River Basin in 2010. 
three major cities as the center and population diffusion distribution area that Dajing River, midstream plain corridor area of the six river systems, midstream plain corridor area of the West River, the core area of Minqin Oasis as the center and presenting a "point-areas-ribbon" structure characteristics that State Road 312, Provincial Highway 211 and 212, Lan-Xin Railway as transport corridors. Population density within the Basin distributes quite differently: The population density of Wuwei City (formerly Chengguan Town area in Wuwei City) reaches 16905.09 people/sq. km becoming the highest one; followed is Jingyang Town of Liangzhou and Sanlei Town of Minqin County, the population respectively is 1345.34 people/sq. km and 711.56 people/sq. km. The east and west sides of Minqin oasis belongs to vast desert area inaccessible, upstream Qilian Mountains are mostly the ethnic communities and the population density is relatively small.

Except Wuwei City, Jinyang Town, and Sanlei Town, YongChang Town, Gaoba Town (including the original Liuba Town), Wunan Town, Qingshui township and Yangxiaba Town (including the original Zhongba Town) located in Liangzhou together form eight high population density and the value of the anomalous areas.

Population distribution structure index analysis. Use of imbalance index and concentration index model of population distribution calculated population distribution structure index change table of the basin sub-counties, as shown in Table 1. Decades since 2000, both imbalance index and concentration Index increase 0.0005, This shows that in the decade the population distribution of Shiyang River Basin was constantly focus on the trend, but changed slightly. It was relate to the level of urbanization continuously improve and population continues to focus on cities in Wuwei City, Jinchang and Minqin County. On the other hand, key management planning of the Shiyang River Basin obtained preliminary results, with the expansion of the scope of desertification in Minqin desert oasis areas, local government began to carry out a variety of measures, such as close pumped well, ecological migrants and reservoir migration, so population is concentrated in a good ecological environment and socio-economic areas. In addition, mountain population migration program represented by Gulang also makes the distribution of population begain changing. In the Shiyang River Basin, imbalance index and the concentration index in Minqin County is the highest, population concentration distribution trend is the most obvious. This is mainly determined by the ecological environment in Minqin County, people can only live within the limited confines of the oasis area, making the degree of population concentration increases. But during 2000-2010 (actual 2009), only Minqin County, the imbalance index and concentration index have been reduced, respectively reduced by 0.0008 and 0.0141 , indicating that in the decade, Minqin County population distribution tend to disperse. This is mainly because of implementation of the Reservoir Resettlement Plan in Hongyashan, making the population distribution is not only focused on the Sanlei Town nearby; In addition, because of Gulang County and the Tianzhu County located in the Qilian Mountains, relative to the middle reaches of the plains corridor area and the Minqin oasis area, the imbalance index and concentration index is relatively low.

Analysis the focus of migration of population distribution. Using calculation model of population centers and ArcGIS9.3 software calculated the location of population distribution center of gravity and the geometric center, as shown in Figure 2. From 2000 to 2010, the focus of population density of the basin significantly offset from north-east Da Liu township to the south-west Liangzhou city direction, but barycentric coordinates still in the Da Liu township territory. Barycentric coordinates moved from $\left(102.711^{\circ} \mathrm{E}, 37.968^{\circ} \mathrm{N}\right)$ in 2000 to $\left(102.700^{\circ} \mathrm{E}, 37.963^{\circ} \mathrm{N}\right)$ in 2010 , it had moved 0.005 degrees to the south in the north-south direction and moved 0.005 degrees to the west in the east-west direction; Obviously, the movement range of the east-west direction is greater than the north-south direction. Barycentric coordinates of the population density in the decade moved

Table 1. Population distribution structure index change in Shiyang River Basin.

\begin{tabular}{|c|c|c|c|c|c|c|c|c|}
\hline Index type & Year & Basin & Jinchang & Wuwi & Liangzhou & Minqin & Gulang & Tianzhu \\
\hline \multirow{3}{*}{$\begin{array}{l}\text { Imbalance } \\
\text { index }\end{array}$} & 2000 & 0.0188 & 0.0812 & 0.0248 & 0.0440 & 0.0905 & 0.0472 & 0.0686 \\
\hline & 2010 & 0.0193 & 0.0812 & 0.0254 & 0.0473 & 0.0897 & 0.0478 & 0.0691 \\
\hline & Increase/decrease & + & 0 & + & + & - & + & + \\
\hline \multirow{3}{*}{$\begin{array}{l}\text { Concentration } \\
\text { index }\end{array}$} & 2000 & 0.6294 & 0.4426 & 0.6501 & 0.4641 & 0.8611 & 0.3913 & 0.3680 \\
\hline & 2010 & 0.6299 & 0.4491 & 0.6501 & 0.4968 & 0.8470 & 0.3908 & 0.3732 \\
\hline & Increase/decrease & + & + & 0 & + & - & - & + \\
\hline
\end{tabular}




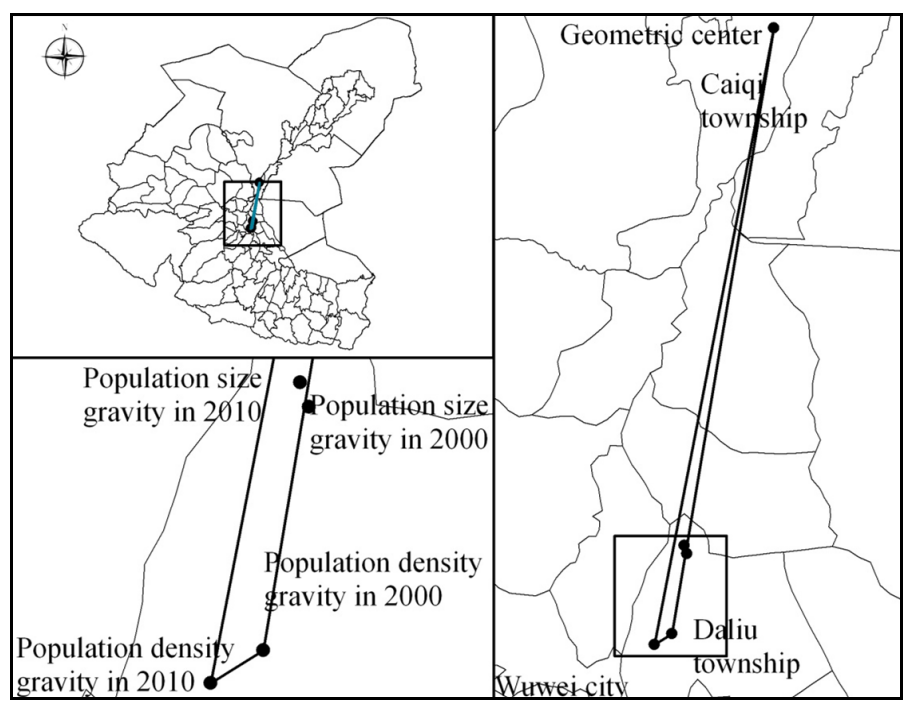

Figure 2. Population distribution center of gravity in Shiyang River Basin (2000 and 2010).

about 1209 meters. The geometric center coordinates of the basin is $\left(102.772^{\circ} \mathrm{E}, 38.286^{\circ} \mathrm{N}\right)$, in the northern Cai Qi township and near Hongyashan Reservoir, distance of the focus of population density changes from 36,364 meters in 2000 to 37,115 meters now, deviated more about 751 meters in ten years. The distance of the population density center of gravity and geometric center was far, mainly caused by the natural and geographical environment of the basin. North-south direction of the movement of the focus of population density is mainly due to Minqin oasis Hongyashan upstream of the reservoir area immigrants and Qilian Mountains population down placement; East-west direction of the movement is mainly due to the gathering role of the center in Jinchang city and Wuwei City. This shows that the urbanization development speed of Wuwei and Jinchang is faster ten years. In addition, it also can be found that the center of gravity position and direction of movement of the population direction of movement of the focus of population density is completely different. This is mainly due to desert and other natural division of the Shiyang River Basin, and township-level administrative divisions of the shape and size difference causes. Therefore, when analysis of population distribution center of gravity changes, it can not use population center of gravity to instead of population distribution in the center of gravity.

Population shift growth analysis. The change of the regional distribution of population is caused by the internal region offset growth, so it can study the reasons for the change of population distribution by the population offset growth of the basin. The offset growth of the Shiyang River Basin population in the decade 20002010 is calculated by taking use of the population offset growth analysis model, as shown in Table 2. The absolute total amount of population growth of the Shiyang River Basin is 43.7 thousand in the decade, population offset growth in the amount of the basin on different levels are not significant. The total migration growth among the townships of the basin is the biggest and is 118.5 thousand; The total migration growth among the internal township unit of 3 prefecture-level cities is 117.3 thousand, slightly less than the total migration growth among the townships, of which only the population of Wuwei offset growth amounted to 108.1 thousand, and the population growth is the fastest; The total migration growth among the internal township unit of 5 counties and 2 regions is the smallest, which is 107.9 thousand: Liangzhou internal population migration is 77.6 thousand, followed by 17.8 thousand people in Gulang County, 0.7 thousand people in Tianzhu County is the minimum. The total population migration growth in the basin on different levels, with each level units for basic statistical unit, is very different, and the total migration growth among the townships of the basin is the largest, which is 118.5 thousand; The total migration growth among 5 counties and 2 regions is 10.6 thousand, far less than the offset between the various township; The minimum of the total migration growth among 3 prefecture-level cities is 1.2 thousand. This shows that in 2000-2010, each level of Shiyang River Basin, townships as the basic statistical unit, in the overall population changes are not significant: for township level, population change is the biggest, population growth rate differences is also the largest; units at all levels as the basic statistical unit, population changes are very great, changes in population growth rate decreases rapidly with the increasing level of 
Administrative Region (SAR) level.

For the population migration growth among the township units, we take use of the standard deviation approach to classification and visualization, shown in Figure 3. Combined with Table 2 and Figure 1 to analysis the population changes in space among various township units of the Shiyang River Basin. In the decade, in the Shiyang River Basin, population offset growth in the spatial distribution and current situation of population density distribution are basically the same. Overall changes in population tend to be concentrated in Wuwei City and Gulang County: the population growth of Wuwei City is the fastest, and population offset growth amounted to 139.044 million; followed by Gulang County, the population offset growth amounted to 83.7201 million. Except Wuwei City, Gulang Town and some towns of the Gulang County, for most towns in the middle reaches plain Corridor district, changes in regional population tended to decrease, the population offset growth was negative value. Especially the most towns within the scope of Liangzhou and Shuangwan Town in the Jinchang City, population offset growth in the amount of absolute value is larger and population to Wuwei City migration

Table 2. The population shift-share analysis between 2000 and 2010 in Shiyang River Basin (million people, \%).

\begin{tabular}{|c|c|c|c|}
\hline Index & 2000-2010 & Index & $2000-2010$ \\
\hline $\begin{array}{l}\text { Total population growth of the } \\
\text { Shiyang River Basin (ABSGR) }\end{array}$ & 4.37 & $\begin{array}{c}\text { Tianzhu County } \\
\text { (VOLSHIFT (intra Tianzhu County)) }\end{array}$ & 0.07 \\
\hline Percentage in the initial years & $1.95 \%$ & $\begin{array}{c}\text { Liangzhou Area } \\
\text { (VOLSHIFT (intra Liangzhou Area)) }\end{array}$ & 7.76 \\
\hline $\begin{array}{l}\text { The total migration growth among the townships } \\
\text { of the basin (VOLSHIFT (total)) }\end{array}$ & 11.85 & $\begin{array}{c}\text { Yongchang County } \\
\text { (VOLSHIFT (intra Yongchang County)) }\end{array}$ & 0.51 \\
\hline $\begin{array}{l}\text { The total migration growth among } 5 \text { counties } \\
\text { and } 2 \text { regions (VOLSHIFT (inter)) }\end{array}$ & 1.06 & $\begin{array}{l}\text { The total migration growth among the internal } \\
\text { township unit of } 3 \text { prefecture-level cities } \\
\text { (VOLSHIFT (intra } 3 \text { cities)) }\end{array}$ & 11.73 \\
\hline $\begin{array}{l}\text { The total migration growth among the internal } \\
\text { township unit of } 5 \text { counties and } 2 \text { regions } \\
\text { (VOLSHIFT (intra)) }\end{array}$ & 10.79 & Among: & \\
\hline Among: & & Wuwei City (VOLSHIFT (intra Wuwei City)) & 10.81 \\
\hline $\begin{array}{c}\text { Gulang County } \\
\text { (VOLSHIFT (intra Gulang County)) }\end{array}$ & 1.78 & $\begin{array}{c}\text { Jiangchang City } \\
\text { (VOLSHIFT (intra Jiangchang City)) }\end{array}$ & 0.93 \\
\hline $\begin{array}{c}\text { Minqin County } \\
\text { (VOLSHIFT (intra Minqin County)) }\end{array}$ & 0.66 & $\begin{array}{l}\text { The total migration growth among } 3 \text { prefecture-level } \\
\text { cities (VOLSHIFT (inter } 3 \text { cities)) }\end{array}$ & 0.12 \\
\hline
\end{tabular}

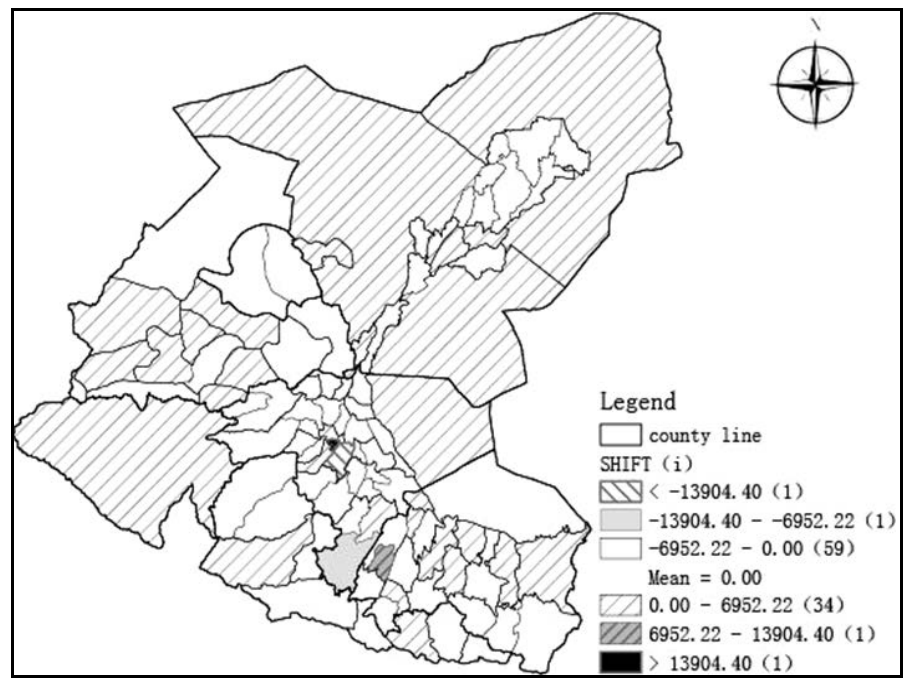

Figure 3. Spatial distribution map of population shift growth based on towanship units in Shiyang River Basin. 
trend is obvious: for combined Gaoba Town (history including Gaoba Town and Liuba County), which is close to Wuwei City and greatly influenced by Wuwei City urbanization, population migration growth absolute value is the largest, the Value achieving to -14292.11 and the rate of decrease of population is the fastest; followed by combined Zhangyi Town (history including the Zhangyi Town, Zhonglu County and Shangquan County), population offset growth amounted to -11572.54. In addition, for the desert area, Qilian high mountain area, and part towns in Gulang County, outside the basin population distribution concentrated area, the growth of population offset is positive, the demographic changes is in the growth trend. But only for Sanlei Town in Minqin, Chengguan Town in Yongchang County, Huangyang Town and Jinta Town in Wuwei, and part towns in Gulang County, the population offset growth is larger, the rest of the regions, offset growth in the amount of the population is relatively small.

\section{Conclusions and Discussion}

This paper studied population distribution characteristics of space and time of the Shiyang River Basin from 2000 to 2010, by analysis of population distribution, population distribution structure index analysis, population distribution center of gravity model and population offset growth analysis model, and mainly drew the following conclusion:

1) Shiyang River Basin population density is low, concentrated in the middle reaches corridor plains area and three population distribution centers of Minqini oasis region, and forms the "point-areas-ribbon" structure characteristics, regional centers, plain corridor areas and transportation corridors as the basis. Basin internal population distribution is quite different, and there are eight high-value anomaly areas, especially Wuwei City, the population density is the largest.

2) The Basin population density of the center of gravity is located in the Liangzhou Daliu country territory; it offset about 1209 m to south-west Wuwei City direction from 2000 to 2010 which offset to east-west direction that was larger than north-south direction. At the same time, the distance of the population density center of gravity from the geometric the center of the basin is relatively far away; for 10 years, it offset about $751 \mathrm{~m}$. The distance of the population center of gravity and the center of gravity of population density is relatively close. But, it can't use the population center of gravity instead of population density of gravity to analyze the changes of population distribution centre of gravity.

3) In ten years, each level of Shiyang River Basin, townships as the basic statistical unit, in the overall population changes are not significant: for township level, population change is the biggest, population growth rate differences is also the largest; units at all levels as the basic statistical unit, population changes are very great, changes in population growth rate decrease rapidly with the increasing level of Administrative Region (SAR) level. Meanwhile, for Prefecture level, the population offset growth of the basin was mainly concentrated in Wuwei City; for county district level, it mainly concentrated in Gulang County the population offset growth of the basin. In other words, in the concentrated area of population distribution, Wuwei City and Gulang Town as the center, the rate of population growth is relatively fast; while in population distribution sparse areas and desert areas, the rate of population growth is relatively low.

4) For ten years, among the basin township units, there are significant changes in population migration. Wuwei City and the Gulang Town are two distinct population migration destination area and population agglomeration area, and there, the population offset growth is also the fastest. Within the Midstream plain corridor area of the basin, except Wuwei City, Gulang Town and some towns of Gulang County, in other towns, the population offset growth is negative, obviously offset to concentrated area of population; In most towns in the sparsely populated area, mainly in Minqin desert area and Qilian mountain area, the population offset growth is positive, but in most towns, the total amount of the offset is relatively small.

Overall, population distribution of the Shiyang River Basin has a significant spatial clustering and population offset growth characteristics. Relying on local unique landscape environment formed its own unique "pointarea-ribbon" distribution structure and for ten years, basin population changes showed obvious characteristics of offsetting to the Wuwei City and Gulang Town. However, in the analysis of the basin, a series of questions will bring some degree of difficulty, such as different shape and area of the township units, frequent changes of administrative divisions, lack of statistical data and inconsistent statistical standards. Characteristics of population distribution are affected by a variety of natural and anthropogenic factors, especially water and traffic impact. Therefore, it needs to consider all relevant factors to faithfully reflect the characteristics of basin population dis- 
tribution, providing strong support to achieve coordinated development of population and environment.

\section{Acknowledgements}

This work was financially supported by China's National Natural Science Foundation (No. 40971078). The graphic data set is provided by Environmental and Ecological Science Data Center for West China, National Natural Science Foundation of China (http://westdc.westgis.ac.cn).

\section{References}

[1] Yang, J., Pu, Y.X., Qin, X.-H. and He, Y.-M. (2010) The Spatial Distribution Pattern of Population and Its Analysis of the Spatio-Temporal Dynamics in Zhejiang Province. Chinese Journal of Population Resources and Environment, Jinan China, 20, 95-99. (In Chinese)

[2] Su, F. and Zhang, P.Y. (2010) Spatio-Temporal Dynamics of Population Distribution in the Middle and Southern Liaoning Urban Agglomeration. Progress in Geography, Beijing China, 29, 96-102. (In Chinese)

[3] Li, X.-Y., Xiao, D.-N., He, X.-Y., et al. (2006) Comparison on Changes and Their Driving Forces of Farmland in Oases of Middle and Lower Reaches: The Case of Liangzhou and Minqin Oases in the Shiyang River Basin. Ecologica Sinica, Beijing China, 26, 671-680. (In Chinese)

[4] Dai, R., Guo, L., Xue, D.-Y. and Sun, F.-M. (2010) Spatio-Temporal Characteristics of Agricultural Population Spatial Distribution in China. Chinese Journal of Population Resources and Environment, Jinan China, 20, 186-189. (In Chinese)

[5] Liu, D.-Q., Liu, Y. and Xue, X.-Y. (2004) China's Population Distribution and Spatial Correlation Analysis. Science of Surveying and Mapping, Beijing China, 29, 76-79. (In Chinese)

[6] Tang, W., Zhong, X.-H. and Zhou, W. (2011) Study on the Evolution of Spatial Distribution Structure of Population in “Three Rivers” Area in Tibet. Chinese Journal of Population Resources and Environment, Jinan China, 21, 159-164. (In Chinese)

[7] Duan, X.-J., Wang, S.-G. and Chen, W. (2008) Evolution of Population Distribution and Growth Shift in Changjiang River Delta. Scientia Geographica Sinica, Beijing China, 28, 139-144. (In Chinese)

[8] Wu, W.Y. and Gao, X.D. (2010) Population Density Functions of Chinese Cities: A Review. Progress in Geography, Beijing China, 29, 968-974. (In Chinese)

[9] Xiang, Y.-B., Zhang, Y. and Zhao, H.-L. (2011) Spatial Evolution Characteristics of Population Distribution in Xiangjiang River Basin. Northwest Population Journal, Lanzhou China, 32, 34-42. (In Chinese)

[10] Cao, Y.H., Li, H.J. and Chen, W. (2004) The Spatial Structure and the Competition Pattern of the Container Port System of China. Acta Geographica Sinica, Beijing China, 59, 1020-1027. (In Chinese)

[11] Li, H.-J. and Liang, L.-K. (2010) Shift-Share Analysis on Competition of Inbound Tourism Destination in China. Geography and Geo-Information Science, Shijiazhuang China, 26, 98-102. (In Chinese) 
Scientific Research Publishing (SCIRP) is one of the largest Open Access journal publishers. It is currently publishing more than 200 open access, online, peer-reviewed journals covering a wide range of academic disciplines. SCIRP serves the worldwide academic communities and contributes to the progress and application of science with its publication.

Other selected journals from SCIRP are listed as below. Submit your manuscript to us via either submit@scirp.org or Online Submission Portal.
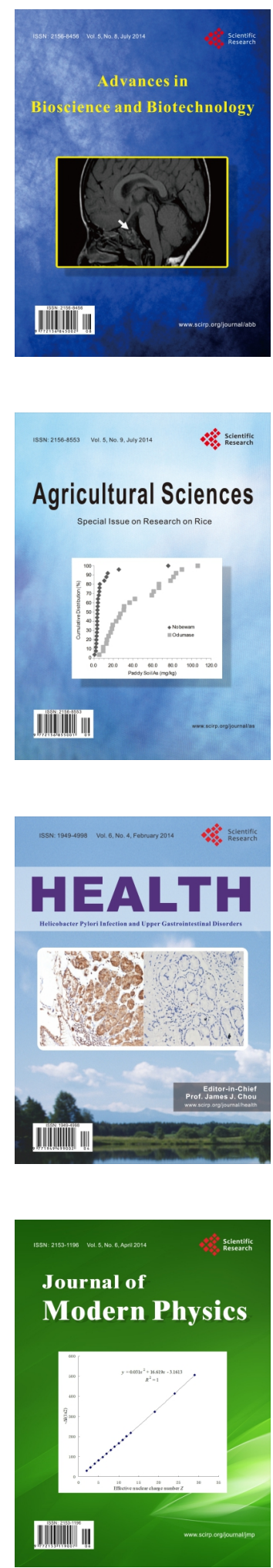
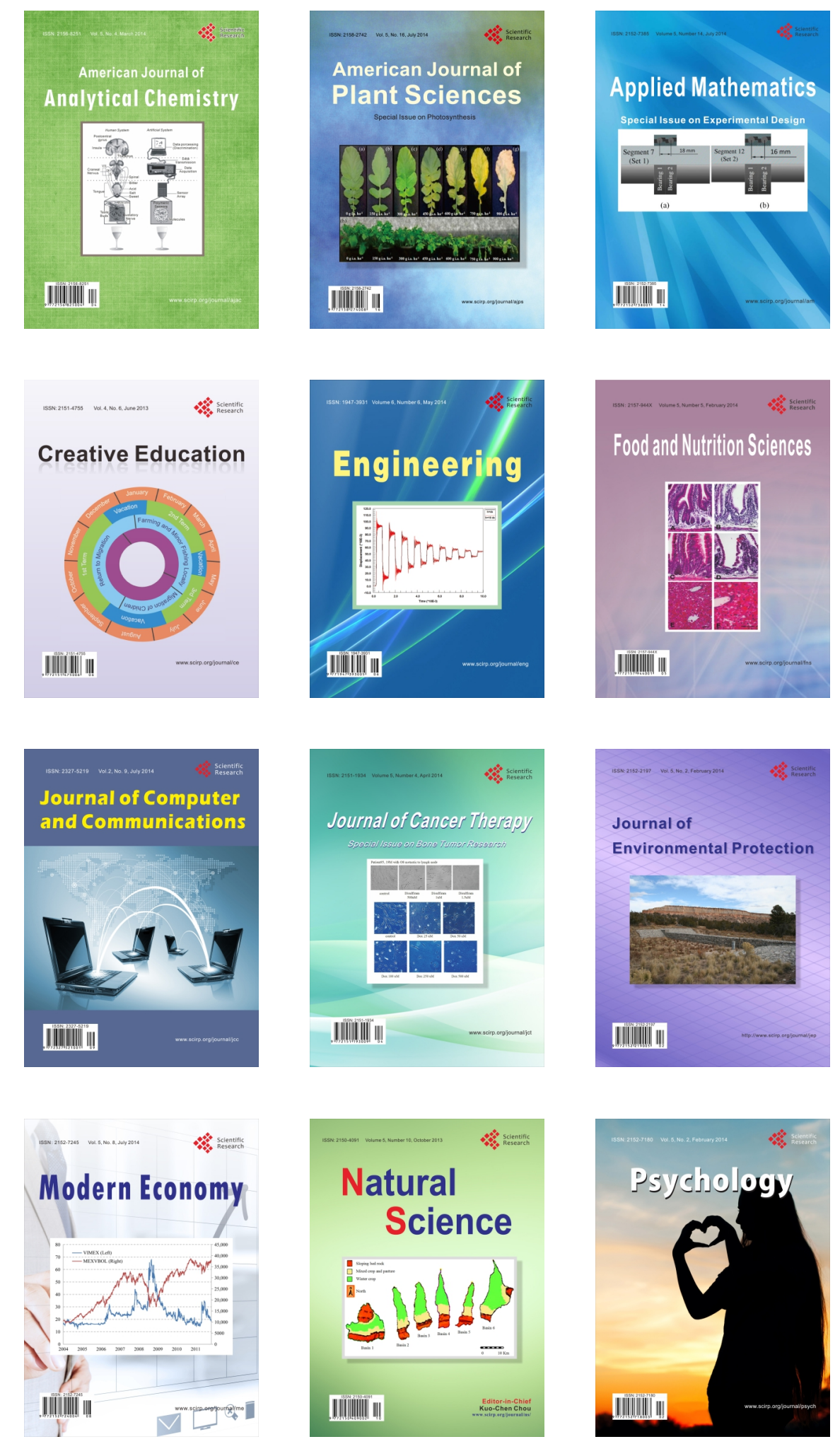